\title{
Rare occurrence of metastasis from lung cancer to the anus: case report and review of the literature
}

\author{
Mohannad Al-Tarakji ${ }^{1}$, Jonas Feilchenfeldt², Abdulrazzaq Haidar ${ }^{3}$, Lajos Szabados ${ }^{4}$, Sherif Abdelaziem ${ }^{1}$, Ali Sayed ${ }^{1}$, \\ Adriana Toro ${ }^{5}$ and Isidoro Di Carlo ${ }^{1,6^{*}}$
}

\begin{abstract}
Background: Anal metastases from lung cancer are infrequent, and there are only 10 published cases. Life expectancy is no longer than 1 year after diagnosis because of the typically advanced stage of disease. Treatment, which is typically inefficient, is administered with the intent to cure or avoid local complications.

Case presentation: We report a case of a patient with non-small cell lung cancer presenting with perianal metastasis mimicking an abscess.

Conclusions: Because perianal masses may be misdiagnosed, patients with lung and other cancers should be evaluated for metastatic disease.
\end{abstract}

Keywords: Lung, Metastases, Anal cancer

\section{Background}

It is very rare for metastases from lung cancers to reside in the anal and/or perianal regions or to associate with multiple metastases in other organs [1]. Accordingly, there are few published reports of this phenomenon. Life expectancy is very short in such cases because this localization represents the dissemination of an aggressive cancer [2]. We describe a patient with non-small cell lung cancer (NSCLC) presenting with perianal metastatic disease mimicking an abscess.

\section{Case presentation}

A 75-year-old man presented on July 2014 with weight loss, loss of appetite, and fatigue. He was a heavy smoker who smoked one pack of cigarettes daily for 40 years. A chest X-ray revealed a homogenous opacity in the leftapical region. Computed tomography $(\mathrm{CT})$ of the chest detected a mass in the left-apical segment $(5.3 \mathrm{~cm} \times$ $6 \mathrm{~cm} \times 6.5 \mathrm{~cm}$ ) with tiny focal calcifications within the

\footnotetext{
*Correspondence: idicarlo@unict.it

'Department of Surgery, Hamad General Hospital, Al Rayyan Road, 3050 Doha, Qatar

${ }^{6}$ Department of Surgical Sciences and Advanced Technologies, "G.F. Ingrassia" University of Catania, Catania, Italy

Full list of author information is available at the end of the article
}

mass, erosion of the left posterior region of the second rib, and multiple mediastinal lymph nodes $<1 \mathrm{~cm}$. Histopathological analysis led to the diagnosis of NSCLC consistent with adenocarcinoma.

A CT scan of the abdomen and pelvis did not detect metastasis, and magnetic resonance imaging did not detect intracranial metastases. Iron deficiency anemia (hemoglobin $=10.2 \mathrm{~g} / \mathrm{dL}$ ) was present. Positron emission tomography (PET) detected intense hypermetabolism in the known left-apical Pancoast tumor, which appeared to invade the thoracic intervertebral foramina with mediastinal and the left axillary lymph node, a suspicious C5 vertebral body metastasis, and intense uptake of tracer in the gastric wall, likely representing a malignancy. Magnetic resonance imaging of the spine detected a left-lung apical tumor with encroachment of the left supraclavicular region as well as extension into the left intervertebral DV1 and DV2 foramina. The tumor displaced, compressed, and invaded the adjacent trunks and distal roots of the brachial plexus with edema surrounding the root of the left neck, the ipsilateral brachial plexus, and the left shoulder with alteration of signal intensities of peri-shoulder muscular anatomy. Upper gastrointestinal 
endoscopy revealed status post Billroth 2 surgery with erosive gastritis without malignancy.

Palliative radiotherapy of the primary tumor was administered along with pemetrexed and carboplatin, and zoledronic acid was continued. In October 2014, the patient presented with pain and tenderness in the left lower chest wall. Ultrasonography revealed a slightly heterogeneous liver mass with small hyperechoic foci $(<1 \mathrm{~cm})$ within the right hepatic lobe and a heterogeneous hypoechoic lesion $(4.6 \times 3.1 \mathrm{~cm})$ in the left adrenal. A CT scan of the chest showed a soft-tissue dense ovoid mass (approximately $3 \mathrm{~cm} \times 4.5 \mathrm{~cm}$ along the right lower chest wall anterior and opposite the anterior ends of the seventh and eighth ribs). A PET scan revealed high tracer uptake into the newly developed bilateral adrenal metastasis and right chest wall lesion. Anal tracer uptake suggested metastasis, and we discontinued testing because the patient was asymptomatic (Fig. 1).

The patient was referred for surgery in February 2015 with a complaint of severe perianal pain and involuntary defecation. A painful, fungating, and red to brown ulcerating mass (approximately $3 \mathrm{~cm} \times 4 \mathrm{~cm}$ ) was present near the anal orifice, which was covered by friable tissue with traces of stool (Fig. 2). Histopathology detected a metastatic, poorly differentiated carcinoma with histomorphology and immunohistochemical findings (CKAE1/AE3 ${ }^{+}$, vimentin ${ }^{+}$) identical to those of the lung tumor (Fig. 3). The patient became severely cachectic and delirious and was short of breath. He died in March 2015 after receiving palliative care.

\section{Discussion}

Lung cancer is the most frequent malignancy with a high mortality rate [3], and patients with NSCLC account for 80-85\%. Adenocarcinomas represent approximately $40 \%$ of NSCLC [4]. When first diagnosed, approximately $40 \%$ of patients with NSCLC harbor distant metastases, and the recurrence rate is high in patients with early disease [4]. Most metastatic lung cancers directly invade other organs and spread through the blood or lymph as well. The brain, bones, adrenal glands, and bone marrow are common metastatic sites of lung cancers compared with the gastrointestinal tract [2].

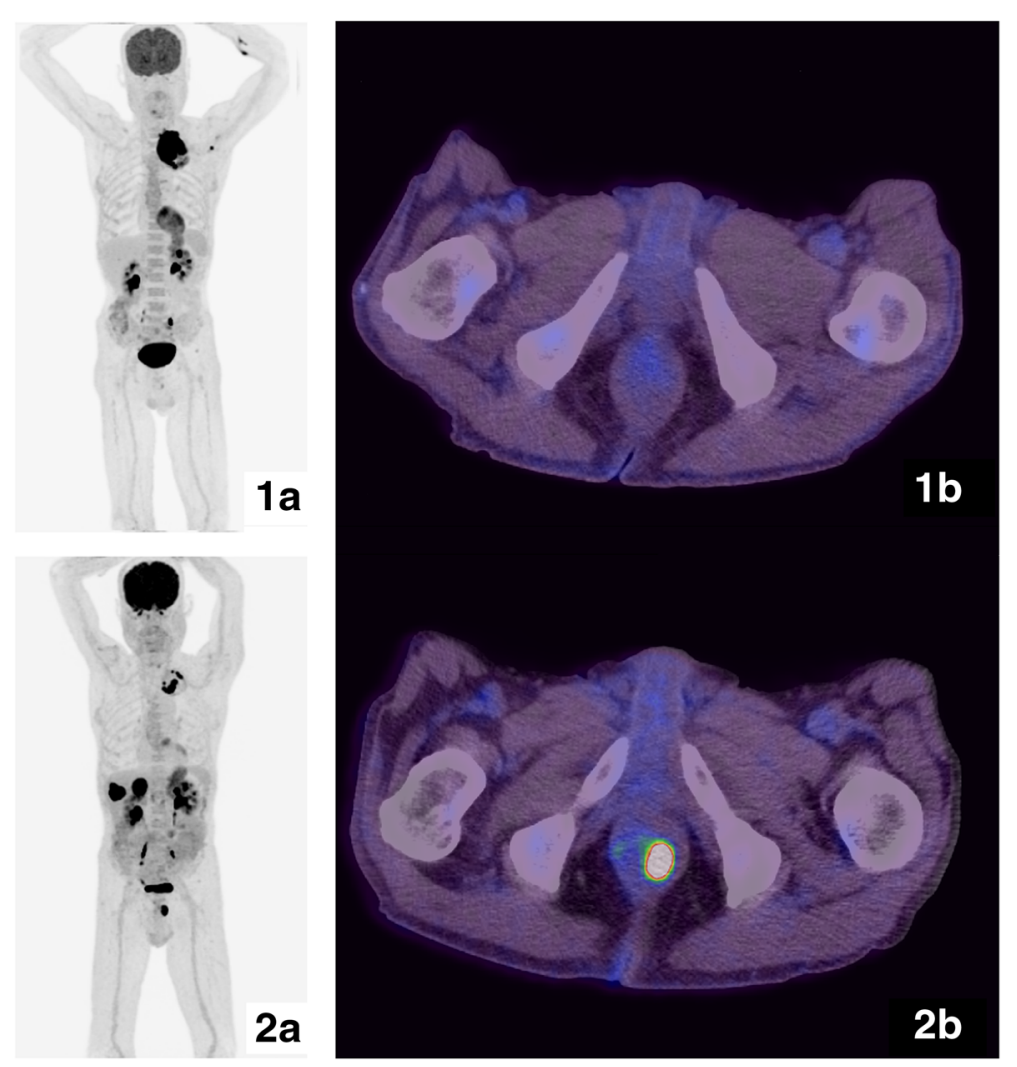

Fig. 1 Maximum intensity projection (MIP) image of ${ }^{18}$ F-fluorodeoxyglucose-staging PET/CT showing hypermetabolic left-lung primary and mediastinal/ left axillary lymph node involvement (1a). Transaxial superimposed PET/CT images showing no focal pathological uptake at the anus (1) b). After four cycles of chemotherapy, the MIP image revealed new involvement of the adrenals, multiple bone metastases, and perianal uptake. Partial metabolic response in the left primary lung tumor (2a). Transaxial superimposed PET/CT images showing intense focal uptake at the left aspect of the anus (2b) 


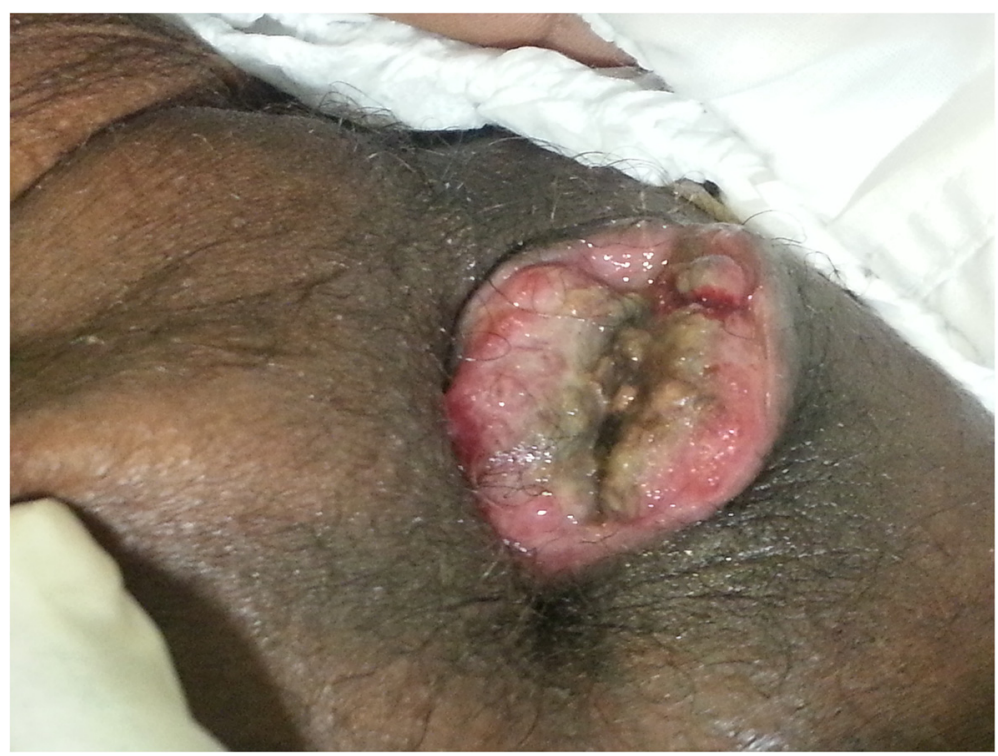

Fig. 2 Anal metastases

Autopsy findings indicate that the rate of gastrointestinal metastases from primary lung carcinomas ranges between 4.7 and $14 \%$ [5]. The esophagus is commonly invaded by direct extension, whereas the stomach is invaded through the lymphatics. One study detected metastatic cells in the small and large bowels [5]. Anal cancers represent $1-2 \%$ of gastrointestinal cancers in the USA; metastatic lesions are less frequent (http://www.fascrs.org/ patients/conditions/analcancer/), and metastatic colon cancer and exfoliation cause most cases [6]. In contrast, metastasis to the intestine from the stomach to the anus is likely caused by retrograde spread through the lymphatics that connect the lung through the mediastine to the intestines [4]. Suspicious hematogenous spread, consequent to cardiopulmonary bypass circuit used to remove a lung tumor protruding into the atrium, has been reported [7]. However, we were unable to determine the route of metastasis in our patient.

There are 11 reports of perianal and anal metastases from primary lung cancers, including the present study (Table 1) [1, 6-14]. The 10 patients with NSCLC included five with adenocarcinomas. Anal metastases were

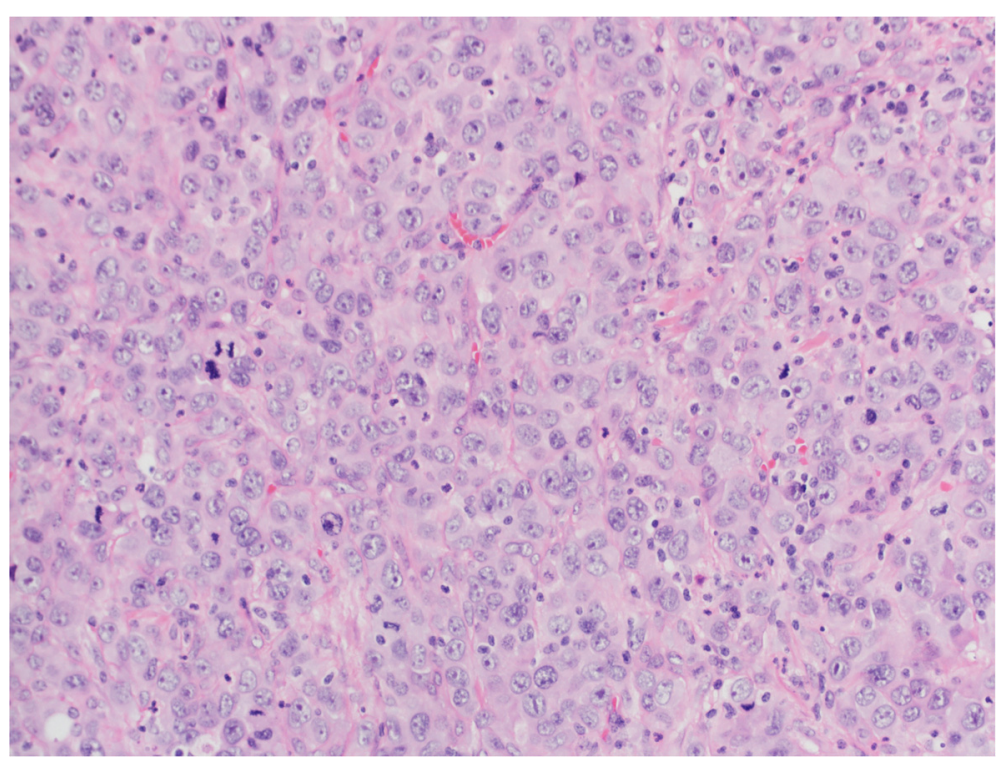

Fig. 3 Histopathological analysis of the anal mass revealed poorly differentiated carcinoma comprising large round cells with abundant cytoplasm and large nuclei with one to two prominent nucleoli 
Table 1 Major characteristics of patients reported in the literature

\begin{tabular}{|c|c|c|c|c|c|c|c|c|c|c|c|}
\hline Year & Journal & First author & Age & Sex & Primary & Metastases & Presentation & Syn or Met & Sin or Mul & Treatment & Survival \\
\hline 1968 & Dis Colon Rectum [3] & Ger R & 49 & M & $\begin{array}{l}\text { Squamous cell } \\
\text { carcinoma (NSCLC) }\end{array}$ & Heart; anus & Rectal hemorrhage & Syn & Mul & $\begin{array}{l}\text { Abdominoperineal } \\
\text { resection }\end{array}$ & $\begin{array}{l}\text { Third postoperative } \\
\text { day. }\end{array}$ \\
\hline 1975 & Dis Colon Rectum [4] & Kanhouwa S & 45 & M & $\begin{array}{l}\text { Anaplastic large-cell } \\
\text { carcinoma (NSCLC) }\end{array}$ & Mediastinum; anus & Anal ulcer & Met & Mul & $\begin{array}{l}\text { CCNU and hydroxyurea; } \\
\text { radiotherapy }\end{array}$ & 10 months \\
\hline 1988 & Gan No Rinsho [5] & Uenura $Y$ & 78 & M & $\begin{array}{l}\text { Mucoepidermoid } \\
\text { carcinoma (NSCLC) }\end{array}$ & Multiple (nr); anus & Perianal mass & Syn & Mul & Radiotherapy & $<1$ year \\
\hline 1994 & Surg Today [6] & Kawahara K & 75 & M & $\begin{array}{l}\text { Squamous cell } \\
\text { carcinoma (NSCLC) }\end{array}$ & Atrium; anus & Anal polyp & Met & Mul & Transanal polypectomy & $\mathrm{nr}$ \\
\hline 2006 & $\begin{array}{l}\text { Gastroenterolo } \\
\text { Clin Biol [7] }\end{array}$ & Wisniewski B & 53 & M & $\begin{array}{l}\text { Adenocarcinoma } \\
\text { (NSCLC) }\end{array}$ & $\begin{array}{l}\text { Anus; mediastinum; } \\
\text { brain }\end{array}$ & Anal abscess & Met & Mul & Incision and drainage & 1 month \\
\hline 2007 & $\begin{array}{l}\text { Southern Medical } \\
\text { Journal [8] }\end{array}$ & Tek I & 50 & M & $\begin{array}{l}\text { Adenocarcinoma } \\
\text { (NSCLC) }\end{array}$ & Anus & Anal abscess & Met & $\operatorname{Sin}$ & $\begin{array}{l}\text { Chemotherapy; drainage } \\
\text { of abscess }\end{array}$ & $\mathrm{nr}$ \\
\hline 2010 & J Buon [1] & Okutur K & 64 & M & $\begin{array}{l}\text { Squamous cell } \\
\text { carcinoma (NSCLC) }\end{array}$ & Pleura; anus & Anal polyp & Met & Mul & $\begin{array}{l}\text { Excision of the polyp; } \\
\text { radiotherapy }\end{array}$ & $\mathrm{nr}$ \\
\hline 2013 & $\begin{array}{l}\text { Clin Resec Hepat } \\
\text { Gastroent[10] }\end{array}$ & Camus M & 53 & $\mathrm{~F}$ & $\begin{array}{l}\text { Adenocarcinoma } \\
\text { (NSCLC) }\end{array}$ & $\begin{array}{l}\text { Liver; mediastinum; } \\
\text { anus }\end{array}$ & Perianal ulceration & Syn & Mul & Chemotherapy & $\mathrm{nr}$ \\
\hline 2014 & Inter Medic [11] & Imai H & 36 & $\mathrm{~F}$ & $\begin{array}{l}\text { Adenocarcinoma } \\
\text { (NSCLC) }\end{array}$ & Subcutaneous; anus & Perianal mass & Met & Mul & $\begin{array}{l}\text { Resection of perianal } \\
\text { mass }\end{array}$ & $\mathrm{nr}$ \\
\hline 2015 & Int J Colorectal Dis [12] & Guerra F & 75 & $\mathrm{~F}$ & $\begin{array}{l}\text { Small cell lung cancer } \\
\text { (SCLC) }\end{array}$ & Anus & Perianal abscess & Met & $\operatorname{Sin}$ & Chemotherapy & $\mathrm{nr}$ \\
\hline 2015 & Present study & Al Tarakji M & 75 & M & $\begin{array}{l}\text { Adenocarcinoma } \\
\text { (NSCLC) }\end{array}$ & Bone; anus & Perianal abscess & Met & Mul & Supportive care & 1 month \\
\hline
\end{tabular}


metachronous in 8/11 patients; other metastatic sites were present, and an abscess was the most prevalent finding. Every abscess or fistula in at-risk patients, such as smokers, has to be considered as a potential metastatic tumor from the lung. Establishing a diagnosis must account for adenocarcinomas arising from a fistula associated with Crohn's disease [15], an anal gland adenocarcinoma [16], or rare metastases from breast [17], pancreatic [18], or renal cancer [19]. Patients should be administered single or combined chemotherapy and radiotherapy, because surgery with curative intent is ineffective and should only address complications. A surgical biopsy can be performed only with diagnosis intent. The palliative surgery can be admitted in case of hemorrhage, external mass with high discomfort for the patient, stenosis, or obstruction of the anal canal [14]. Nevertheless, survival does not exceed 1 year from diagnosis. Together, the present and published cases indicate that perianal masses may be misdiagnosed and patients with NSCLC or other cancers should be evaluated for metastatic disease.

\section{Conclusions}

Because perianal masses may be misdiagnosed, patients with lung and other cancers should be evaluated for metastatic disease.

\section{Abbreviations \\ NSCLC non-small cell lung cancer, CT computed tomography, PET positron emission tomography}

\section{Acknowledgements}

The authors declare that no acknowledgements have to be done.

\section{Funding}

The authors declare that no funds have been received.

\section{Availability of data and materials}

The availability of the data and material section concerning the case report is related to all the diagnostic examinations that the patients have submitted during their hospitalization. The publication of all these data has been authorized by the Medical Research Center of the Hamad General Hospital.

\section{Authors' contributions}

MAT, JF SA, SA, and LS participated in the care of the patient. MAT and AT performed the literature review and drafted the manuscript. AH obtained the pathological data. IDC revised the manuscript. All authors read and approved the final manuscript.

\section{Competing interests}

The authors declare that they have no competing interests.

\section{Consent for publication}

The consent for publication of the manuscript and the related images from the patients and/or their relatives have been obtained by the Medical Research Center of Hamad General Hospital.

\section{Ethics approval and consent to participate}

The ethical approval has been received by the Medical Research Center of the Hamad General Hospital concerning the publication of this manuscript and any accompanying images. A copy of this document is available for review by the Editor-in-Chief of this journal.

\section{New software}

The authors declare that no new software has been used.

\section{Author details}

'Department of Surgery, Hamad General Hospital, Al Rayyan Road, 3050 Doha, Qatar. ${ }^{2}$ National Center for Cancer Care and Research, Doha, Qatar. ${ }^{3}$ Department of Pathology, Hamad General Hospital, Doha, Qatar. ${ }^{4}$ PET/CT Center, Clinical Imaging Department, Hamad General Hospital, Doha, Qatar. ${ }^{5}$ Department of Surgery, Patti Hospital, Messina, Italy. ${ }^{6}$ Department of Surgical Sciences and Advanced Technologies, "G.F. Ingrassia" University of Catania, Catania, Italy.

Received: 22 December 2015 Accepted: 21 May 2016 Published online: 08 June 2016

\section{References}

1. Okutur K, Arslan K, Bozkurt M, Barlan M, Oz B, Demir G. Squamous cell carcinoma of the lung with anal canal metastasis. J BUON. 2010;15:194.

2. Mulder MC, Kist JW, Consten ECJ, Verheijen PM. Gastrointestinal metastasis as the first presentation of lung carcinoma. Int J Colorectal Dis. 2012;27:839-40.

3. Deffebach ME, Humphrey L. Lung cancer screening. Surg Clin North Am. 2015;95:967-78.

4. Travis WD, Brambilla E, Riely GJ. New pathologic classification of lung cancer: relevance for clinical practice and clinical trials. J Clin Oncol. 2013;31: 992-1001.

5. Yang CJ, Hwang JJ, Kang WY, et al. Gastro-intestinal metastasis of primary lung carcinoma: clinical presentations and outcome. Lung Cancer. 2006;54: 319-23.

6. Kawahara K, Akamine S, Takahashi T, Nakamura A, Kusano H, Nakagoe T, Nakazaki T, Ayabe H, Tomita M. Anal metastasis from carcinoma of the lung: report of a case. Surg Today. 1994;24:1101-3.

7. Ger R, Reuben J. Squamous-cell carcinoma of the anal canal: a metastatic lesion. Dis Colon Rectum. 1968:11:213-9.

8. Kanhouwa S, Burns W, Matthews M, Chisholm R. Anaplastic carcinoma of the lung with metastasis to the anus: report of a case. Dis Colon Rectum. 1975;18:42-8.

9. Uemura Y, Ohtsuki Y, Sonobe H, Nakamura S, Takeuchi T, Fujishita M, Miyoshi I. Perianal skin metastasis in a case of lung cancer. Gan No Rinsho. 1988:34:1054-6.

10. Wisniewski B, Vuong P, Balaton A, Bauer P, Brugger S, Janzen J. Métastase anale d'un cancer broncho-pulmonaire. Gastroenterol Clin Biol. 2006;30:471-2.

11. Tek I, lyidir OT, Utkan G, Ceyhan K, Buyukcelik A, Yalcin B, Demirkazik A. Lung cancer metastasis mimicking gluteal abscess. South Med J. 2007;100: 334-5.

12. Camus M, de Parades V, Fléjou JF, Atienza P, Zeitoun JD. Synchronous perianal metastasis of lung adenocarcinoma: report of a case. Clin Res Hepatol Gastroenterol. 2013;37:e143-4.

13. Imai H, Inafuku K, Wakuda $K$, Ono A, Taira T, Kenmotsu H, Watanabe R, Naito T, Murakami H, Ito I, Endo M, Tanabe H, Nakajima T, Takahashi T. Perianal metastasis of non-small cell lung cancer. Intern Med. 2014;53:1149-52.

14. Guerra F, Amore Bonapasta S, Tumbiolo S, Gentile E, Coratti A. Lung cancer metastasis to the external anal sphincter mimicking perianal abscess. Int J Colorectal Dis. 2015;30:581-2.

15. Tarazi R, Nelson RL. Anal adenocarcinoma: a comprehensive review. Semin Surg Oncol. 1994;10:235-40.

16. Thomas DJ, Thompson MR. Implantation metastasis from adenocarcinoma of sigmoid colon into fistula in ano. J R Soc Med. 1992;85:361.

17. Cerdan FJ, Torres-Melero J, Arias-Diaz J, Cantero R, Pelayo A, Balibrea Cantero IL. Anal metastases from breast carcinoma. Coloproctology. 1995;17:41-4.

18. Ejtehadi F, Chatzizacharias NA, Brais RJ, Hall NR, Godfrey EM, Huguet E, Praseedom RK, Jah A. Colonic and anal metastases from pancreato-biliary malignancies. World J Gastroenterol. 2014;20:3693-7.

19. Sawh RN, Borkowski J, Broaddus R. Metastatic renal cell carcinoma presenting as a hemorrhoid. Arch Pathol Lab Med. 2002;126:856-8. 